\title{
ANALYTICAL METHOD DEVELOPMENT FOR THE ESTIMATION OF DARUNAVIR BY DIAZOTIZATION AND COUPLING BY VISIBLE SPECTROPHOTOMETRY
}

\author{
VIJAYALAKSHMI R*, ANJANI D, SRIRAMAMURTHY M, DHANARAJU M D
}

Research Lab, GIET School of Pharmacy, Rajahmahendravaram, Andhra Pradesh, India. Email: vijayalakshmigsp@gmail.com

Received: 08 June 2018, Revised and Accepted: 02 July 2018

ABSTRACT

Objectives: This proposed work describes simple and extraction free visible methods for the estimation of darunavir ethanolate (DNV) in bulk and tablet formulations. The methodology involves diazotization of DNV with nitrous acid followed by coupling with chromotropic acid (CA) (Method A)/ Bratton Marshall Reagent (Method B)/ $\alpha$-naphthol (Method C) to form colored products.

Methods: All the methods were developed using a PerkinElmer (LAMBDA 25) UV-Visible spectrophotometer interfaced with UV Win lab software and $1 \mathrm{~cm}$ quartz cells.

Results: Spectrophotometrically, DNV is estimated at $520 \mathrm{~nm}, 544 \mathrm{~nm}$, and $464 \mathrm{~nm}$ for the reddish-pink color produced by CA, dark violet color with NED, and dark-greenish yellow with $\alpha$-naphthol, respectively. The linear relationship was observed between absorbance and the corresponding concentration of drug in the range of 100-350 $\mu \mathrm{g} / \mathrm{mL}, 10-100 \mu \mathrm{g} / \mathrm{mL}$, and 10-60 $\mu \mathrm{g} / \mathrm{mL}$ for Methods $\mathrm{A}$, B, and C, respectively.

Conclusion: The colorimetric methods were extensively validated as per the ICH guidelines. The developed methods were proven to be more accurate and precise by the statistical analysis.

Keywords: Darunavir, Chromotropic acid, Bratton Marshall reagent, $\alpha$-Naphthol.

(C) 2018 The Authors. Published by Innovare Academic Sciences Pvt Ltd. This is an open access article under the CC BY license (http://creativecommons. org/licenses/by/4. 0/) DOI: http://dx.doi.org/10.22159/ajpcr.2018.v11i11.27830

\section{INTRODUCTION}

Darunavir (DNV) ethanolate is chemically [1S, 2R] -3-[[(4 amino phenyl) sulfonyl](2-methyl propyl) amino]-2-hydroxy-1-(phenyl methyl)propyl]-carbamic acid (3R,3aS,6aR) hexa hydro furo [2,3-b] furan-3-yl ester mono ethanolate (Fig. 1) used as an oral retroviral agent and an inhibitor of human immunodeficiency virus protease [1]. It prevents HIV replication by binding to the enzyme's active site, thereby preventing the dimerization and the catalytic activity of the HIV-1 protease. It selectively inhibits the cleavage of HIV-encoded GagPol polyproteins in virus-infected cells, which prevents the formation of mature infectious virus particles and coadministered with ritonavir.

Few reversed-phase high-performance liquid chromatography methods [1-6], UV/visible methods [7-10], and high-performance thinlayer chromatography (HPTLC) methods [11] were found through the extensive literature search on the quantization of DNV in pure and dosage forms. The existing HPLC and HPTLC methods are laborious, timeconsuming and need sample pretreatment. By virtue, spectrophotometry is the instrumental technique of choice eventually by its simplicity, sensitivity, and low cost for the underdeveloped and developing nations. The existing visible methods were based on oxidation or substitution reactions. Spectrophotometric methods based on diazotization and coupling method were not reported earlier. Based on the need for more simple analytical methods, the present work describes three simple, timeeffective, and sensitive methods based on the diazotization and coupling process for the quantization of DNV in pure and tablet dosage forms.

\section{METHODS}

\section{Equipment}

Double-beam PerkinElmer (LAMBDA 25) UV-vis spectrophotometer interfaced with UV WIN lab software and $1 \mathrm{~cm}$ quartz cuvettes were used for spectral measurements. Sartorius balance was used for weighing the samples.
Chemicals

DNV was obtained as a gift sample from Aurobindo Pharma Ltd., Hyderabad. Ethanol, chromotropic acid (CA), Bratton-Marshall Reagent (BMR), $\alpha$-naphthol, ammonium sulfamate, hydrochloric acid, and sodium nitrite were used for the experimental work. All the chemicals used in the experimental work were of AR Grade.

\section{Preparation of stock solution of DNV}

$25 \mathrm{mg}$ of DNV was accurately weighed and transferred to a $25 \mathrm{~mL}$ volumetric flask and dissolved and diluted to final volume with ethanol. The resulting solution has a concentration of $1 \mathrm{mg} / \mathrm{mL}$.

\section{Preparation of reagents}

\section{$0.2 \% W / V B M R$}

$200 \mathrm{mg}$ of BMR was weighed and dissolved to make $100 \mathrm{~mL}$ with water.

\section{$0.5 \% \mathrm{~W} / \mathrm{V}$ sodium nitrite}

$500 \mathrm{mg}$ of sodium nitrite was weighed and dissolved to make $100 \mathrm{~mL}$ with water.

\section{$0.5 \% \mathrm{~W} / \mathrm{V}$ ammonium sulfamate}

$500 \mathrm{mg}$ of ammonium sulfamate was weighed and dissolved to make $100 \mathrm{~mL}$ with water.

\section{$0.2 \% \mathrm{~W} / \mathrm{V} C A$}

$200 \mathrm{mg}$ of CA was weighed and dissolved in a mixture of $75 \mathrm{~mL}$ of concentrated sulfuric acid and $33 \mathrm{~mL}$ of distilled water.

\section{$0.2 \% W / V \alpha$-naphthol}

$200 \mathrm{mg}$ of $\alpha$-naphthol was weighed and dissolved to make $100 \mathrm{~mL}$ with ethanol. 
$5 \mathrm{~N} \mathrm{HCl}$

$42.5 \mathrm{~mL}$ of concentrated hydrochloric acid was taken into a $100 \mathrm{~mL}$ of volumetric flask and dissolved in distilled water, and the final volume was made up to $100 \mathrm{~mL}$ with distilled water.

Procedure for calibration standards (Method A)

In a series of $10 \mathrm{~mL}$ volumetric flasks, $1-4 \mathrm{~mL}$ of working standard solution of DNV was pipette out, $0.2 \mathrm{~mL}$ of hydrochloric acid, $0.2 \mathrm{~mL}$ of sodium nitrite, $0.2 \mathrm{~mL}$ of ammonium sulfamate, and $0.7 \mathrm{~mL}$ of CA were added and then kept aside for $15 \mathrm{~min}$, and then, the final volume was made up to $10 \mathrm{~mL}$ with water. The absorbance of the reddishpink colored chromogen was measured at $520 \mathrm{~nm}$ against the reagent blank.

\section{Procedure for calibration standards (Method B)}

In a series of $10 \mathrm{~mL}$ volumetric flasks, $0.1-1 \mathrm{~mL}$ of working standard solution of DNV was pipette out, $0.6 \mathrm{~mL}$ of hydrochloric acid, $0.5 \mathrm{~mL}$ of sodium nitrite, $0.6 \mathrm{~mL}$ of ammonium sulfamate, and $0.6 \mathrm{~mL}$ of BMR were added, and then, the final volume was made up to $10 \mathrm{~mL}$ with ethanol. The absorbance of the dark violet-colored product was measured at $544 \mathrm{~nm}$ against the reagent blank.

\section{Procedure for calibration standards (Method C)}

In a series of $10 \mathrm{~mL}$ volumetric flasks, $0.1-0.6 \mathrm{~mL}$ of working standard solution of DNV was pipetted out, $0.8 \mathrm{~mL}$ of hydrochloric acid, $0.4 \mathrm{~mL}$ of sodium nitrite, $0.8 \mathrm{~mL}$ of ammonium sulfamate, and $0.8 \mathrm{~mL}$ of $\alpha$-naphthol were added, and then, the final volume was made up to 10 $\mathrm{mL}$ with ethanol. The absorbance of the dark greenish-yellow-colored product was measured at $464 \mathrm{~nm}$ against the reagent blank.

\section{Assay procedure for Methods A-C}

20 tablets of commercial samples of DNV were accurately weighed and powdered. Tablet powder equivalent to $25 \mathrm{mg}$ was weighed, then dissolved and diluted to $25 \mathrm{~mL}$ using ethanol, and filtered. Then, the solution was subjected to the respective procedure described above and the absorbance was noted.

\section{RESULTS AND DISCUSSION}

\section{Optimization of the method}

The spectral characteristics of all the methods using CA, BMR, and $\alpha$-naphthol reagents were studied as per standard optimization parameters $[12,13]$

\section{Method optimization}

\section{Order of addition and reagent concentration}

The order of addition of reagents, optimum concentration, and volume was studied on the basis of their ability to give a maximum absorbance. To find out whether the order of addition and reagent concentration has any influence on absorbance intensity, suitable concentration of the reagent and order of addition of reagents were studied by varying one parameter at a time keeping the other constant. The results are presented in Table 1.

\section{Effect of temperature and stability of colored products}

Effect of temperature on reaction conditions was studied; if the temperature is maintained above $40^{\circ} \mathrm{C}$, the intensity of absorbance reduces; lowering the temperature has no effect on absorbance. Hence, these methods were carried out at room temperature. The formation of the colored complex was complete in 15 min time intervals at room temperature for Method A. For Methods B and C, the color formation was complete within 4-5 min. The stability of colored product was studied by taking the absorbance at various time intervals, and the color of the reaction products was emphasised to be stable for $2 \mathrm{~h}$.

\section{Method validation}

All the methods were validated as per the ICH guidelines [I4] for accuracy, precision, linearity, limit of detection (LOD), limit of quantification (LOQ), ruggedness, and robustness, and the results were found to be satisfactory. Regression parameters are presented in Table 2.

\section{Linearity and range}

At the described experimental conditions, the standard calibration curves were constructed by plotting an increase in absorbance with concentration.

The linear correlation found between absorbance and concentration of DNV is presented in Table 2. The statistical parameters given in the regression equation were calculated from the calibration graphs. The high values of the regression coefficients and low values of y-intercepts of the regression equations proved the linearity of the calibration curves.

\section{LOD and LOQ}

LOD and LOQ were determined by analyzing progressively lower concentrations of standard solution using optimized conditions, and the results are presented in Table 2.

\section{Precision}

The precision of the proposed methods was assessed by determining the relative standard deviation (RSD) of six replicate analyses on the

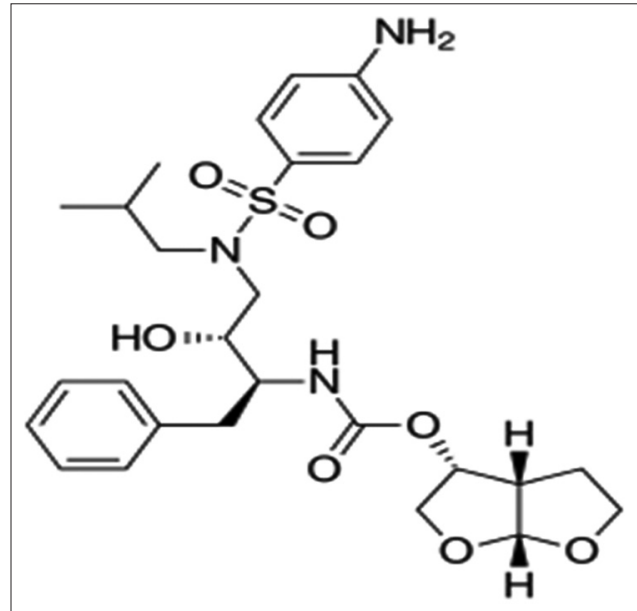

Fig. 1: Chemical structure of Darunavir

Table 1: A study of the order of addition and reagent concentration

\begin{tabular}{ll}
\hline Method & Order of addition and reagent concentration \\
\hline Method A & DNV+HCl $(0.2 \mathrm{~mL})+\mathrm{SN}(0.2 \mathrm{~mL})+\mathrm{AS}(0.2 \mathrm{~mL})$ \\
& $+\mathrm{C} . \mathrm{A}(0.7 \mathrm{~mL})$ \\
Method B & DNV+HCl $(0.6 \mathrm{~mL})+\mathrm{SN}(0.5 \mathrm{~mL})+\mathrm{AS}(0.6 \mathrm{~mL})$ \\
& $+\mathrm{NED}(0.6 \mathrm{~mL})$ \\
Method C & DNV+HCl $(0.8 \mathrm{~mL})+\mathrm{SN}(0.4 \mathrm{~mL})+\mathrm{AS}(0.8 \mathrm{~mL})$ \\
& $+\alpha-\mathrm{N}(0.8 \mathrm{~mL})$ \\
\hline
\end{tabular}

Table 2: Optical and regression parameters for Methods A, B, and $\mathrm{C}$

\begin{tabular}{llll}
\hline Parameters & Method A & Method B & Method C \\
\hline$\lambda_{\text {max, }} \mathrm{nm}$ & 520 & 544 & 464 \\
Beer's law range $(\mu \mathrm{g} / \mathrm{mL})$ & $100-350$ & $10-100$ & $10-60$ \\
$\begin{array}{l}\text { Molar extinction } \\
\text { coefficient }\left(\mathrm{L} . M o l \mathrm{C}^{-1} \mathrm{~cm}^{-1}\right)\end{array}$ & $5.2 \times 10^{4}$ & $1.2 \times 10^{5}$ & $1.9 \times 10^{5}$ \\
Sandell's sensitivity & $10 \times 10^{-3}$ & $6.0 \times 10^{-3}$ & $3.0 \times 10^{-2}$ \\
$\left(\mu \mathrm{g} / \mathrm{cm}^{2}\right) / 0.001$ abs unit & & & \\
$\mathrm{LOD}, \mu \mathrm{g} / \mathrm{mL}$ & 4.8044 & 1.4095 & 0.8583 \\
$\mathrm{LOQ} \mu \mathrm{g} / \mathrm{mL}$ & 16.0146 & 4.6984 & 2.8611 \\
Slope $(\mathrm{m})$ & 0.008717 & 0.02119 & 0.03255 \\
Intercept $(\mathrm{b})$ & -0.003320 & 0.01716 & 0.005964 \\
Correlation coefficient $(\mathrm{r})$ & 0.9999 & 0.9999 & 0.9999 \\
\hline
\end{tabular}

LOD: Limit of detection, LOQ: Limit of quantification 
Table 3: Results of precision studies for Methods A-C

\begin{tabular}{|c|c|c|c|c|c|c|}
\hline \multirow[t]{2}{*}{ Parameter } & \multicolumn{2}{|l|}{ Method A } & \multicolumn{2}{|l|}{ Method B } & \multicolumn{2}{|l|}{ Method C } \\
\hline & Intraday* & Inter day* & Intraday & Interday* & Intraday* & Interday* \\
\hline Concentration $(\mu \mathrm{g} / \mathrm{mL})$ & 200 & & 90 & & 40 & \\
\hline Mean abs & 1.754 & 1.7601 & 1.9206 & 1.9258 & 1.3223 & 1.3251 \\
\hline SD & 0.0014 & 0.0004 & 0.0004 & 0.0003 & 0.0004 & 0.0003 \\
\hline$\%$ RSD* & 0.0842 & 0.0231 & 0.0256 & 0.0201 & 0.0372 & 0.0293 \\
\hline
\end{tabular}

${ }^{*}$ n: Average of six determinations, SD: Standard deviation, RSD: Relative standard deviation

Table 4: Accuracy table for Methods A-C

\begin{tabular}{|c|c|c|c|c|c|}
\hline Method & Standard amount added & Drug in formulation & \%recovery & SD & $\%$ RSD $n=3$ \\
\hline \multirow[t]{3}{*}{ A } & 200 & 150 & 99.466 & 0.00577 & 0.0058 \\
\hline & & 200 & 99.666 & 0.00577 & 0.00579 \\
\hline & & 250 & 99.846 & 0.00577 & 0.00578 \\
\hline \multirow[t]{3}{*}{ B } & 40 & 20 & 99.233 & 0.00577 & 0.00581 \\
\hline & & 40 & 99.646 & 0.00577 & 0.00579 \\
\hline & & 60 & 99.943 & 0.00577 & 0.00577 \\
\hline \multirow[t]{2}{*}{$\mathrm{C}$} & 30 & 20 & 99.456 & 0.00577 & 0.0058 \\
\hline & & 40 & 99.95 & 0.01 & 0.010005 \\
\hline
\end{tabular}

Table 5: Assay results for Methods A-C

\begin{tabular}{llll}
\hline Method & Formulation & Label claim (mg) & Amount found (mg) \\
\hline A & Daruvir (Cipla Ltd.) & 300 & 299.19 \\
B & & 300 & 299.20 \\
C & & 300 & 299.35 \\
\hline
\end{tabular}

*Mean of three determinations, SD: Standard deviation

same solution containing a fixed concentration of DNV (within Beer's law limit). The low \% RSD of the intra- and inter-day repeatability studies corroborates precision of the method. Table 3 represents the results of precision studies

\section{Robustness and ruggedness}

Robustness was ascertained by the low \%RSD by narrow alteration of the optimized parameters. System-to-system/analyst-to-analyst variability study was conducted for ruggedness studies. The \%RSD was found to be $<1$ by both studies, which corroborates that the method is rugged and robust.

\section{Accuracy}

The validity and accuracy of the proposed methods were further assessed by recovery studies using the standard addition technique. For this purpose, a known quantity of pure drug at three different levels was spiked to the fixed and known quantity of pre-analyzed formulation samples, and the concentration of the drug was estimated by the proposed methods. The results given in Table 4 establish that the methods were reproducible by low SD and \%RSD. No interference was evidenced from the common formulation excipient.

\section{Application of the proposed method to the formulation}

To evaluate the proposed methods, they were applied to the determination of DNV in commercial formulations. The recoveries are close to $100 \%$, indicating that there is no serious interference in samples. The good agreement between these results and known values indicates the successful application of the proposed methods for the determination of DNV in formulations. The results are given in Table 5.

\section{DISCUSSION}

The proposed visible methods were successfully developed for the estimation of DNV. The methods were specific and selective by diazotization and coupling. The spectral analysis of DNV shows maximum absorbance at $520 \mathrm{~nm}, 544 \mathrm{~nm}$, and $464 \mathrm{~nm}$ by Methods A-C, with linearity range between 100 and $350 \mu \mathrm{g} / \mathrm{mL}, 10$ and 100 , and 10 and 60 by Methods A-C, respectively. The very low LOD and LOQ obtained by the proposed methods proven the methods to be sensitive. The methods were validated in terms of accuracy, precision, and robustness as per the ICH guidelines. The low percentage relative $\mathrm{SD}$ value proves high precision of the method with absolute robustness. The regression analysis depicted in Table 2 shows a correlation coefficient nearer to 1 . The results of the accuracy studies were nearer to $100 \%$. These methods will reduce the tedious procedures involved in the preparation of sample and solvent system as like HPLC. The application of the proposed methods to the tablet formulation revealed that no excipients of tablet formulation interfere with the analysis of DNV by all proposed methods.

\section{CONCLUSION}

The new, cost-effective, simple, and sensitive visible methods using CA, NED, and $\alpha$-naphthol were developed for the determination of DNV in bulk and pharmaceutical formulations. The developed methods were also validated. From the statistical data, it was found that the proposed methods were accurate, precise, and reproducible and can be successfully applied to the analysis of the same and could make a better alternative to the existing methods.

\section{AUTHORS' CONTRIBUTIONS}

The authors contributed to various degrees in the design and fabrication of the research work. The team assisted the experimentation and drafted the article together.

\section{CONFLICTS OF INTEREST}

The authors declare no conflicts of interest.

\section{REFERENCES}

1. Babu GR, Rao AL, Rao JV. Development and validation of novel HPLC method for estimation of darunavir in pharmaceutical formulations. Int J Res Pharm Chem 2013;3:438-3. 
2. Reddy BV, Jyothi G, Reddy BS, Raman NV, Reddy KS, Rambabu C. A novel stability-indicating reversed-phase high-performance liquid chromatography (HPLC) method has been developed for the quantitative determination of Darunavir ethanolate, an HIV-1 protease inhibitor. J Chromatogr Sci 2013;51:471-6.

3. Satyanarayana L, Naidu SV, Rao MN, Kumar A, Suresh K. A reverse phase HPLC method was developed for the estimation of darunavir in tablet dosage form. Asian J Res Pharm Sci 2011;1:74-6.

4. Manisha M, Pranali JG, Anuja VP, Mashish S. RP-HPLC Method for determination of darunavir in bulk and pharmaceutical preparations. Int J Pharm Sci Rev Res 2013;21:20-3.

5. Patel BN, Suhagia CN, Bhanubhai N, Chaganbhai NP. RP-HPLC method development and validation for estimation of darunavir ethanolate in tablet dosage form. Int J Pharm Pharm Sci 2012;4:270-4.

6. Mastannama SK, Sirisha VS, Alekhya G, Haritha K, Arunbabu V. New validated RP-HPLC method for estimation of darunavir in bulk and dosage form. Int Res J Pharm 2014;5:13-6.

7. Rao KV, Phanindra B, Rajesh K. Spectrophotometric method for estimation of darunavir ethanolate by using MBTH reagent in bulk and pharmaceutical dosage form. Inventi Rapid 2013;4:1-3.

8. Mastanamma SK, Sirisha VS. Validated visible spectrophotometric method for estimation of darunavir in bulk and pharmaceutical dosage form using 1, 2 naphthoquinone 4-sulphonate reagent. World J Pharm Res 2014;3:4615-24.

9. Vijayalakshmi R, Anjani D, Kumari SS, Bhuvaneswari S, Dhanaraju MD. Oxidative coupling method for the estimation of darunavir and capecitabine by visible spectrophotometry. Int J Pharm Tech Res 2016;9:146-74

10. Vijayalakshmi R, Ramya YN, Mani AD, Dhanaraju MD. Spectrophotometric determination of darunavir ethanolate by condensation technique. Int J Pharm Tech Res 2016;9:301-6.

11. Deshpande BP, Santosh RB. Development and validation of stabilityindicating HPTLC method for determination of darunavir ethanolate and ritonavir. Int J Pharm Pharm Sci 2015;7:66-71.

12. Vijayalakshmi R, Ramya YN, Dhanaraju MD. Method development for quantification of oxidation complexes of nadolol and resveratrol by visible spectrophotometry. Int J Pharm Pharm Sci 2015;5:304-7.

13. Jawad AA, Kadhim KH. Spectrophotometric determination of metoclopramide hydrochloride in bulk and pharmaceutical preparations by diazotization-coupling reaction. Int J Pharm Pharm Sci 2013;15:294-8.

14. ICH-Q2B Validation of Analytical Procedures: Methodology International Conference on Harmonization of Technical Requirements for Registration of Pharmaceuticals for Human use, Geneva, Switzerland; 1996 